\title{
Perceived changes of specific attitudes, perceptions and behaviors during the Corona pandemic and their relation to wellbeing
}

Arndt Büssing ( $\square$ arndt.buessing@uni-wh.de )

Witten/Herdecke University https://orcid.org/0000-0002-5025-7950

Daniela Rodrigues Recchia

Witten/Herdecke University

Rudolf Hein

Philosophical-Theological Academy Münster

Thomas Dienberg

Philosophical-Theological Academy Münster

\section{Research Article}

Keywords: changes of perceptions, corona pandemic, wellbeing, life satisfaction, change of attitudes, spirituality, awe, gratitude

Posted Date: November 13th, 2020

DOl: https://doi.org/10.21203/rs.3.rs-107651/v1

License: (9) This work is licensed under a Creative Commons Attribution 4.0 International License. Read Full License 
Health and Quality of Life Outcomes - HQLO-D-20-00419R1 (Accepted for publication 04.11.2020)

Perceived changes of specific attitudes, perceptions and behaviors during the Corona pandemic and their relation to wellbeing

Arndt Büssing,,${ }^{1,2} \S$ Daniela Rodrigues Recchia, ${ }^{3}$ Rudolf Hein, ${ }^{2}$ Thomas Dienberg ${ }^{2}$

${ }^{1}$ Professorship Quality of Life, Spirituality and Coping, Faculty of Health, Witten/Herdecke University, 58313 Herdecke, Germany

${ }^{2}$ IUNCTUS - Competence Center for Christian Spirituality, Philosophical-Theological Academy, 48149 Münster, Germany

${ }^{3}$ Chair of Research Methods and Statistics in Psychology, Faculty of Health, Witten/Herdecke University, 58448 Witten, Germany

$\S$ Corresponding author

Email addresses:

arndt.buessing@uni-wh.de

Daniela.RodriguesRecchia@uni-wh.de

r.b.hein@uni-muenster.de

th.dienberg@iunctus.de 


\begin{abstract}
Background

During the COVID-19 pandemic, most people had to cope with the restrictions of the lockdown, leaving them to their fears, insecurity and isolation. On the other hand, due to the unexpected 'extra time' there was room for new experiences and for personal reflections on what is essential in life, to perceive nature and relations more consciously etc. We, therefore, intended to analyze perceived changes of attitudes and behaviors during the time of lockdown, and whether these perceptions would contribute to personal wellbeing during the pandemic.
\end{abstract}

\title{
Method
}

An anonym cross-sectional online survey was performed for data collection, using standardized questionnaires, i.e., the WHO-Five Well-being Index (WHO-5), Brief Multidimensional Life Satisfaction Scale (BMLSS), Awe/Gratitude scale (GrAw-7), and the newly developed Perceived Changes Questionnaire (PCQ).

Results

Within the number of respondents $(n=1,277)$, women were predominating $(67.5 \%)$.

Participants' mean age was $50.9 \pm 14.9$ years. Exploratory factor analyses showed that the 24item Perceived Changes Questionnaire differentiated five factors that would account for $61 \%$ of variance: 1) Nature / Silence / Contemplation (Cronbach's alpha =.87), 2) Spirituality $($ Cronbach's alpha $=.83), 3)$ Relationships $($ Cronbach's alpha $=.80), 4)$ Reflection on life $($ Cronbach's alpha $=.74), 5)$ Digital media usage $($ Cronbach's alpha $=.74)$. Strongest changes were observed for Relationships and Nature / Silence / Contemplation. Perceived changes were stronger among older persons, among persons with higher wellbeing, and among those who relied on their faith as a resource. These changes were predicted best by a person's 
perception of wondering awe in distinct situations with subsequent feelings of gratitude. Stepwise regression analyzes revealed that participants' wellbeing was explained best by low perceived burden and high life satisfaction $\left(\mathrm{R}^{2}=.46\right)$. Awe/gratitude, perceived changes in terms of Nature / Silence / Contemplation and low Reflections of live are further variables that would predict a person's wellbeing among the COVID-19 pandemic,

Conclusions

During the Corona pandemic, people tried to find ways to adapt to the outcomes of the restrictions. The perceived changes of attitudes and behaviors can be interpreted in terms of a reappraisal strategy. These can be measured with the extended version of the PCQ which was found to have good quality indices and a plausible factor structure. The reported changes contribute to persons' wellbeing only to some extend, indicating that they represent an independent quality of relevance in peoples' life.

Keywords: changes of perceptions; corona pandemic; wellbeing; life satisfaction; change of attitudes; spirituality, awe; gratitude

\section{Introduction}

Like in almost every country in the world, the severity of the COVID-19 pandemic brought about in Germany a complete social and economic lockdown in spring 2020. The public health system has focused on diagnosis, quarantine, and supportive treatment possibilities for infected patients [1,2]. Managing of people at risk was seen as a challenging task by health professional, because there is currently no cure or reliable treatments established $[3,4]$. This insecurity resulted in fears and worries among the general population, too, because the only preventive option seems to be personal hygiene and social distancing. Several might thus experience phases of loneliness, depression or 'defeat stress' which is characterized by an 
inability to "cope with adversity" [5]. Most persons in Germany complied with the individual and social restrictions, implemented by the government, generally staying in their homes. As a consequence, especially the elderly people (and many others) felt isolated from their friends and relatives [6]. Others missed the collaborative networks at their distant workplace and had to deal with so much (boring) 'extra time'. Some experienced a degree of fear getting into contact with potentially infected persons $[4,7]$. So, they avoided direct contact and allowed themselves to go to the grocery and pharmacies only (which actually was in some countries the strictest form of lockdown). Persons, suffering from chronic diseases and also those with acute symptoms of illness refrained from visiting hospitals, were very hesitant to visit their medical practitioners simply because they were afraid to risk a viral infection $[4,7]$.

Persons in lockdown had to cope with their own fears and insecurity and the outcomes of being isolated on the one hand (which can be regarded as stressors or burden), while on the other hand, they also made new experiences, as they had a lot of 'extra time' for personal reflections about what is seen as essential in their life, to perceive nature and their relations more consciously etc. (which can be seen as putative resources to cope). We, therefore, intended to analyze the perceived changes of attitudes and behaviors during the time of lockdown. Flash interviews among tumor patients from Germany have documented the restrictions in daily life and loneliness as the main burdens during the crisis [4]. With those taking part in the survey, faith proved to be a major factor of stability and stronghold.

What about perceived changes in a non-diseases group of persons? Apart from concerns of loneliness and feeling restricted, many used the 'extra time' of the lockdown to spend more time outdoors, to perceive nature more intensely, to spend more time with their partner and their children - and generally to have more time for themselves. This 'extra time' could be used as a chance to reflect on those things which may give meaning in life, to reflect on what is essential in life, maybe also as a hint to change important aspects of life, to be more aware 
of nature and of people in the neighborhood, and to deal more consciously ('mindfully') with them. Further, some persons during the Corona pandemic have experienced that these restricted times allowed them to focus more on their own spiritual resources (meditation/prayer), and, thus, some have enjoyed the 'silence', while others feared this 'silence' because they became aware of their loneliness and insecurity. These experiences can be related to the concepts of 'spiritual transformation' [8,9] or 'posttraumatic growth' $[10,11]$. Spiritual transformation was described also in HIV infected persons by Kremer \& Ironson [12], with more intense spiritual practices, meaning finding, self-perception and selfknowledge. With HIV-infected persons, spiritual transformation related to better wellbeing, less distress and better coping [13]. Posttraumatic growth in cardiac surgery survivors was predicted by religious coping and partner support [10]; interestingly, perceived spiritual support was a mediator of these effects.

During the Corona pandemic González-Sanguino et al. [14] performed an online survey among people from Spain and found that $18.7 \%$ were depressed, $21.6 \%$ perceived anxiety and 15.8\% had PTSD symptoms. In their study spiritual wellbeing was the best protector for symptomatology, and loneliness for depression, anxiety and PTSD. In a study among tumor patients from Germany it was found that the topics meaning in life, having (religious) trust, stable relationships, mindful encounter with nature, and times of reflection were important to them to cope with the restrictions during the Corona pandemic [7]. In that study, a short version of the Perceived Changes Questionnaire was used; an extended version of this assessment instrument will be used in this study, that aimed to analyze main factors of spiritual and personal coping strategies during the Corona pandemic in terms of more conscious awareness, religious and personal (social) bonding, particularly in the light of perceived changes of attitudes and behavior linked to relationships, awareness of nature and 
quietness, interest in spiritual issues, or feelings of worries and isolation. We also asked whether these perceptions would contribute to personal wellbeing during the pandemic.

Despite the fact that this is an explorative analysis of distinct perceptions shaped during the Corona crisis, we had several assumptions relevant for the selection of variables. Research indicates that personal faith can be a relevant resource to cope with difficult times $[15,16,17]$, and thus, we assume that even within a secular society several may rely on their faith as a strong hold in difficult times to cope, and that this will increase their awareness for the Sacred in their life and conscious encounter also with the world around. Similarly, those who are able to stop and be aware of the beauty around and who are emotionally or 'spiritually' touched by specific situations (in terms of wondering awe and subsequent feelings of gratitude) $[18,19]$, perceive more positive changes in their attitudes and behaviors. Thus, male and female religious living in monastic structures who are (due to their specific life style) trained to be more aware of the Sacred in their life and are more active in spiritual practices and rituals, might be more able to change their attitudes and behaviors compared to persons with other life styles. This group was chosen as a contrasting group to persons from different other professions (i.e., administration, economy, education, health, and other). Thus, we assume that perceived burden due to the COVID-19 pandemic ("Stressors") may be the cause to perceive life concerns differently, while specific attitudes (i.e., having faith as a resource and being able to perceive feeling of wondering awe and gratefulness on the one hand, and frequency of meditation and praying as indicators of a person's spiritual practice) would be positively associated ("Resource") as positive influencing variables.

\section{Material and Methods}

\section{Recruitment of patients}


Participants were recruited within 4 weeks via snowball sampling in different networks in Germany, i.e., university students and staff, research collaborators, religious orders and church communities, Rotary Club members, Facebook sites, etc. (from June 9 to June 21, 2020). As well, all were invited to spread the information about this survey in their personal networks. In Germany, the lockdown started at March 16; during end of May 2020 several restrictions were relaxed step by step.

Participants were assured confidentially and were informed about the purpose of the study and data protection information at the starting page of the online survey. By filling in the anonymous questionnaire, interested persons consented to participate. Neither concrete identifying personal details nor IP addresses were recorded to guarantee anonymity.

\section{Measures}

\section{Perception of Changes}

The Corona pandemic and related social and individual restrictions may have changed specific attitudes, perceptions and behaviors. To assess which changes due to the Corona pandemic were observed, we used an extended version of the previously tested 12 -item short version of the Perception of Change Questionnaire (PCQ) [7]. The 32 statements of this extended version cover the following topics: more intense relations, mindful perception of nature, times of quietness, spirituality, connectedness / loneliness, meaning in life, hope and fear. These refer to the experiences communicated by various persons during the start of the pandemic. And they are related to the concept of 'spiritual transformation' $[8,9]$ and 'posttraumatic growth' [11]. The respective items were introduced by the phrase "Due to the current situation...", which referred to the Corona pandemic. Agreement or disagreement was scored on a 5-point scale ( 0 - does not apply at all; 1 - does not truly apply; 2 - neither yes nor 
no; 3 - applies quite a bit; 4 - applies very much). Items phrasings, factorial structure and internal consistency coefficients are depicted in Table 2.

\section{Well-being Index}

To assess participants' well-being, we used the WHO-Five Well-being Index (WHO-5). This short scale avoids symptom-related or negative phrasings and measures well-being instead of absence of distress [20]. Representative items are "I have felt cheerful and in good spirits" or "My daily life has been filled with things that interest me". Respondents assess how often they had the respective feelings within the last two weeks, ranging from at no time (0) to all of the times (5). Here we report the sum scores ranging from 0 to 25 . Scores $<13$ would indicate reduced wellbeing or even depressive states. Using the alternative WHO-5 sum scores referred to a $100 \%$ level [0-100], which is also used in literature, scores $<50$ are indicative for reduced wellbeing and scores $<28$ for clinical depression [21]. Using these WHO-5 sum scores [0-100], persons with scores $<13$ would have a WHO5 sum score of $33.9 \pm 11.7$ in this sample, while persons with moderate wellbeing (scores 13-16) would have a sum score of $65.6 \pm 6.9$, and those with high wellbeing (scores $>18$ ) would have a WHO-5 sum score of $82.4 \pm 6.5$

\section{Life satisfaction}

Life satisfaction was measured using the Brief Multidimensional Life Satisfaction Scale (BMLSS) [22]. The items of the BMLSS address intrinsic (oneself, life in general), social (friendships, family life), external (work situation, where one live) and prospective dimensions (financial situation, future prospects) of life satisfaction as a multifaceted construct. The internal consistency of the instrument was found to be good in the validation 
study (Cronbach's alpha $=.87)$. In this study, the 10-item version was employed that includes satisfaction with the health situation and abilities to deal with daily life concerns (BMLSS10). We added two further items addressing satisfaction with support by friends and cohesion among friends.

\section{Perception of burden}

Perceived restrictions of daily life, of being under pressure / stressed, anxiety / insecurity, loneliness / social isolation and restrictions of financial-economic situation due to corona pandemic were measured with five numeric rating scales (NRS), ranging from 0 (not at all) to 100 (very strong) as described [7]. These five variables can be combined to a factor termed "Stressors" with good internal consistency in this sample (Cronbach's alpha $=.801)$. This "Stressor" scale is strongly related to reduced wellbeing (WHO-5: $r=-.59)$ and reduced life satisfaction (BMLSS-10: $\mathrm{r}=-.53$ ) as related constructs in this sample, but marginally only with awe/gratitude (GrAw-7: $\mathrm{r}=-.10)$ as an unrelated construct.

\section{Indicators of Spirituality}

Perceptions of wondering awe and subsequent gratitude is a perceptive aspect of secular spirituality which is relevant also to less or non-religious persons [18]. To address times of pausing for 'wonder' in specific stations (mainly in the nature), we measured perceived awe and subsequent feelings of gratitude as a perceptive aspect of spirituality with the 7-item Awe/Gratitude scale (GrAw-7) [18]. This scale has good psychometric properties (Cronbach's alpha $=0.82)$ and uses items such as "I stop and then think of so many things for which I'm really grateful", "I stop and am captivated by the beauty of nature", "I pause and stay spellbound at the moment" and "In certain places, I become very quiet and devout". Thus, awe / gratitude operationalized in this way is a matter of an emotional reaction towards an 
immediate and 'captive' experience. All items were scored on a 4-point scale ( 0 - never; 1 seldom; 2 - often; 3 - regularly), referred to a 100-point scale.

To measure also a more specific forms of religiosity, we added item A37 from the Reliance on God's Help scale [22], which asks whether faith is a strong hold in difficult times.

Agreement or disagreement was scored on a 3-point scale (0 - disagreement; 2- indifference; 3- agreement. This item was used as a differentiating variable to assess intrinsic religiosity in terms of an attitude.

The frequency of spiritual/religious practices such as meditation or praying was assessed with a 4-grade scale ranging from never, to at least once per month, at least once per week, and at least once per day as described [7].

\section{Corona pandemic irritations}

Several persons reported that they were "Irritated or unsettled by different statements about the danger and the course of the corona infection in the public media" [4,7]. Agreement to these statements was scored from not at all, a little, somewhat to very much.

\section{Health behaviors}

Health behaviors such as Alcohol consumption, usage of relaxing ("mood lifting") drugs, physical activity / sporting, and walking outside in the nature were measured with a 4-grade scale (never, at least once per month, at least once per week, at least once per day) as described [7]. 
Statistical analysis

Descriptive statistics, analyses of variance (ANOVA), internal consistency (Cronbach's coefficient $\alpha$ ) and factor analyses (principal component analysis using Varimax rotation with Kaiser's normalization) as well as first order correlation (Spearman rho) and stepwise regression analyses were computed with SPSS 23.0. Moderation analysis was used to investigate the possible influence of a variable (gender) on the effect of one predictor (awe/gratitude) when regressing on the response variable (Perceived Changes). This is a strategical approach to estimate the conditional effects of a moderator. The moderation analysis was performed with $\mathrm{R}$ 4.0.3.

Given the exploratory character of this study, significance level was set at $p<.01$. With respect to classifying the strength of the observed correlations, we considered $r>.5$ as a strong correlation, an $\mathrm{r}$ between .3 and .5 as a moderate correlation, an $\mathrm{r}$ between .2 and .3 as a weak correlation, and $\mathrm{r}<.2$ as negligible or no correlation.

\section{Results}

Description of the sample

The online survey was accessed by 1,509 persons, and 162 did not start the survey $(10.7 \%)$. Among the 1,374 starting persons, 97 provided only basic sociodemographic data, but did not respond to the subsequent items; these were regarded as non-responders ( $7.1 \%$ of the starters). These non-responders did not significantly differ from the responders with respect to gender, age, lack of religious affiliations or COVID-19 infection testing (data not shown). 
Within the responders $(n=1,277)$, women were predominating $(67.5 \%)$ (Table 1). Participants mean age was $50.9 \pm 14.9$ years. Their professions are divers, ranging from administration, economy, education, medicine, church and other (i.e. coaching, psychology, kindergarden teacher, yoga teacher, journalism, culture, social work, police, agriculture, service, and retired persons). A majority had a Christian affiliation (76\%), and 19\% none. Nevertheless, only for $51 \%$ their faith was a strong hold in difficult times.

Several were irritated or unsettled by different statements about the danger and the course of the corona infection in the public media (44\% somewhat to very much). A COVID-19 infection was found in $0.8 \%$ (10 persons), $8 \%$ were negatively tested, most not at all (91\%) (Table 1). Within the non-completers, five persons were COVID-19 infected, 9 persons negatively tested and 78 not yet tested.

Wellbeing and health behavior in the sample

With respect to the generally accepted standard that WHO-5 scores $<13$ may indicate reduced low wellbeing or even depressive states, in our sample $30 \%$ would have had low life satisfaction (WHO-5 score $<13$ ); 40\% moderate life satisfaction (WHO-5 scores between 15 and 18 ) and 31\% high life satisfaction (WHO-5 scores $>18$ ). General life satisfaction was in the upper third, while perceived daily life restrictions were in a moderate range. Feelings of being under pressure / stress, anxiety / insecurity, loneliness / social isolation and restrictions by financial-economic situation were in the lower range, indicating only weak burden (Table $1)$.

With respect to respondents' health behavior, Alcohol consumption was found $37 \%$ at least once per week and $8 \%$ at a daily level, while mood lifting drugs were rarely used (3\% at least once per day). Physical activity / sporting was found by 53\% at least once per week and by 
$20 \%$ at a daily level. Walking in nature was found by $52 \%$ at least once per week and by $31 \%$ at a daily level. Further, meditation was practiced by $21 \%$ at least once per week and by $30 \%$ at a daily level, while praying was practices by $15 \%$ at least once per week and by $49 \%$ at a daily level (Table 1).

Perception of changes of attitudes and behaviors

To better summarize and calculate patients' perceived changes in attitudes and behavior, we intended to combine these as factors and thus performed reliability and factor analyses of the 32 intended items. A Kaiser-Mayer-Olkin value of .89 (as a measure for the degree of common variance) indicated that the item pool is suited for principal component factor analysis.

During this process some items were eliminated: Three items referring to the intended topic of isolation were eliminated due to a weak corrected item to scale correlation (c15 I feel cut off from life; c16 I feel restricted in my freedom; c17 I lack social contacts); however, these three had an acceptable internal consistency (Cronbach's alpha $=.78)$ and were used as an addition scale to address perceived "Restrictions". Also, three items referring to perceived loss had to be eliminated because of a too weak reliability (c27 I find that our society is falling apart more and more; c28 I rather fear for the future; c30 I lost my belief); their internal consistency as a putative factor was not satisfactory $($ Cronbach's alpha $=.53)$. Exploratory factor analysis pointed to six factors with eigenvalues $<1$, among them a 2-item factor which refers to the two "hope" items c25 ("I have the hope that we ('afterwards') as global mankind will pay more attention to each other and stick together") and c26 ("I would like to work to ensure that the world becomes fairer in the future"); however, their internal consistency was not satisfactory $($ Cronbach's alpha $=.57)$ and both items were eliminated from the item pool. The 
remaining 24 items had a very good internal consistency (Cronbach's alpha $=.91)$ and differentiated in five factors that would account for $61 \%$ of variance (Table 2 ):

1. Nature / Silence / Contemplation (7 items; Cronbach's alpha =.868), combines the topics experience of silence and mindful perceptions, i.e., taking time for silence, enjoying times of silence, going outdoors more often and perceive nature more intensely, and subsequently more time to reflect what is really important in life and to deal more consciously with own concerns, and being more relaxed than before

2. Spirituality (5 items; Cronbach's alpha $=.827)$, refers to interest in spiritual issues, confidence in a higher support, praying, and attending digital worship /service offers

3. Relationships (6 items; Cronbach's alpha $=.800$ ), includes all items addressing connectedness in its various forms, i.e., taking more time for my family and friends, perceiving the relationship with my partner, family and friends more intensely, feeling closer to the people in my household, importance of relationships to feel safe and at home, and the intention to be more friendly with others

4. Reflection on life (3 items; Cronbach's alpha $=.744)$, combines two meaning items (concerned about meaning and purpose of life and concerned about the lifetime one has) and one isolation / loneliness item (more intensive perception of loneliness)

5. Digital media usage (3 items; Cronbach's alpha $=.742$ ), refers to digital forms of connectedness (i.e., which allow to share in the world, to connected to friends, and to be inspired by specific websites).

The difficulty index of these 24 items was (mean score $2.33 / 4=$ ) 0.58 ; all were in the acceptable range of 0.2 and 0.8 (Table 2). 
Perceptions of change within the sample

The most frequently perceived changes were more intense Relationships and Perception of nature / Silence / Contemplation, followed by Reflection on life and Digital media usage, and Spirituality, while Perceived Restrictions scored lowest (Table 3).

Women scored significantly higher on Nature / Silence / Contemplation and Reflection of life than men, less pronounced also for Spirituality and Relationships, but not for Digital media usage or Perceived Restrictions (Table 3). The higher the age is, the more intense the addressed changes were perceived, and the less severe the restrictions.

Persons who relied on their faith as a strategy to cope had significantly higher perceptions of change in all addressed fields, and lower perceptions of Restrictions (Table 3). Similarly, male and female (catholic) religious scored significantly stronger on Nature / Silence / Contemplation, Spirituality, and Reflection on life and had lower Perceived Restrictions, while they did not differ with respect to Relations and Digital media usage lower. When participants had low wellbeing, all perceived changes scores significantly lower compared to persons with moderate or high wellbeing, while the usage of digital media was similar (Table $3)$.

Perceptions of change and their correlation with perceived burden, life satisfaction, spirituality and health behaviors

The factors were moderately to strongly intercorrelated, particularly Nature / Silence / Contemplation and Relationships, while Digital media usage was best related with Spirituality, and weakly only with the other perceptions (Table 4). Perceived restrictions were marginally only related with the perceived changes. 
Burden and stress related indicators were moderately to strongly correlated with Perceived Restrictions, and either not at all or marginally only with the perceived changes (Table 4).

Participants' wellbeing (WHO-5) was weakly associated with Nature / Silence /

Contemplation. Their general life satisfaction (BMLSS-10) was weakly positively related with Relationships and negatively with Reflection of life. In contrast, Perceived Restrictions were moderately related with reduced wellbeing and life satisfaction (Table 4).

Faith as a strong hold was strongly related to Spirituality, while Awe/Gratitude as a perceptive form of (secular) spirituality was moderately related to Nature / Silence / Contemplation, Spirituality and Relationship, and marginally only with Digital media usage or low Perceived Restrictions.

Participants' frequency of health behavior, particularly usage of relaxing drugs, alcohol consumptions and physical activity / sporting were not relevantly associated with perceived changes. However, walking outside in nature was weakly correlated with Nature / Silence / Contemplation (which is sound from a theoretical point of view). Frequency of meditation was moderately associated with Nature / Silence / Contemplation and Spirituality, while frequency of praying was strongly related with Spirituality.

Predictors of perceived changes

Because several variables significantly related to the perceived changes during the Corona pandemic, stepwise regression analyses were performed to identify which of these variables would best predict these perceived changes (Table 5). Religious brothers and sisters have significantly higher Faith as a strong hold ( $85 \%$ vs $47 \%$; $\left.<<0.0001, \mathrm{Chi}^{2}\right)$ and significantly higher awe/gratitude scores $(73.1 \pm 15.4$ vs $66.0 \pm 18.1 ; p<.0001$, Mann-Whitney-U test $)$ than 
the other participants. Awe/Gratitude seems to be a more general indicator of secular spirituality which is moderately related to frequency of meditation $(\mathrm{r}=.44)$ and praying $(\mathrm{r}=.32)$, and to Faith as a strong hold [r=.35]. Thus, we included the burden and wellbeing related variables, indicators of spirituality (Faith as strong hold, awe/gratitude, and also frequency of meditation and praying), walking outside in nature as a relevant behavior during the lock down restrictions, and also gender, age and living in a monastery as independent variables.

Nature / Silence / Contemplation was predicted by eight variables, explaining altogether $24 \%$ of variance. The best predictor was awe/gratitude (which alone explains $15 \%$ of variance), followed by meditation, walking outside in nature and wellbeing. Age, gender, faith as a strong hold or living in a monastery were less relevant predictors.

Spirituality was predicted by seven variables, which explain $55 \%$ of variance. Best predictor was praying, which both would explain $43 \%$ of variance, and further faith as hold in difficult times (which adds $6 \%$ of explained variance), meditation and awe/gratitude age (which together would add further $4 \%$ of variance). Life satisfaction, age and living in a monastery were less relevant predictors in this model.

Relationships were predicted by five variables, which explain only $15 \%$ of variance, best awe/gratitude, which alone would explain $10 \%$ of variance, and further by life satisfaction, and perceived burden ("stressors"), while walking in nature and faith as a strong hold were less relevant predictors.

Reflections of live were predicted by five variables, which explain $20 \%$ of variance, best again by awe/gratitude (which would explain $7 \%$ of variance), and further by low life satisfaction (which adds further $8 \%$ of explained variance), and by higher age and by perceived burden 
("stressors") (which together would add 4\% of explained variance). Praying was a less relevant predictors in this model.

Usage of digital media was predicted by four variables, albeit with neglectable predictive power $\left(\mathrm{R}^{2}=.05\right)$. These variables are thus not reliable to predict observed digital media usage changes.

Perceived Restrictions were predicted by four variables, which explain $38 \%$ of variance, best by perceived burden ("stressors"), which alone would explain $36 \%$ of variance, while the other three predictors were of minor relevance.

Moderation Analysis

Because persons living in a monastery and gender in general showed significant differences for awe/gratitude and for perceived changes, we tested whether both variables may moderate the relationship between awe/gratitude and perceived changes. Regarding Changes: Nature, Silence / Contemplation the strongest effect was found for gender as a moderator of awe/gratitude, albeit with weak effect (Figure 1). For all other changes no significant moderation was detected (data not shown).

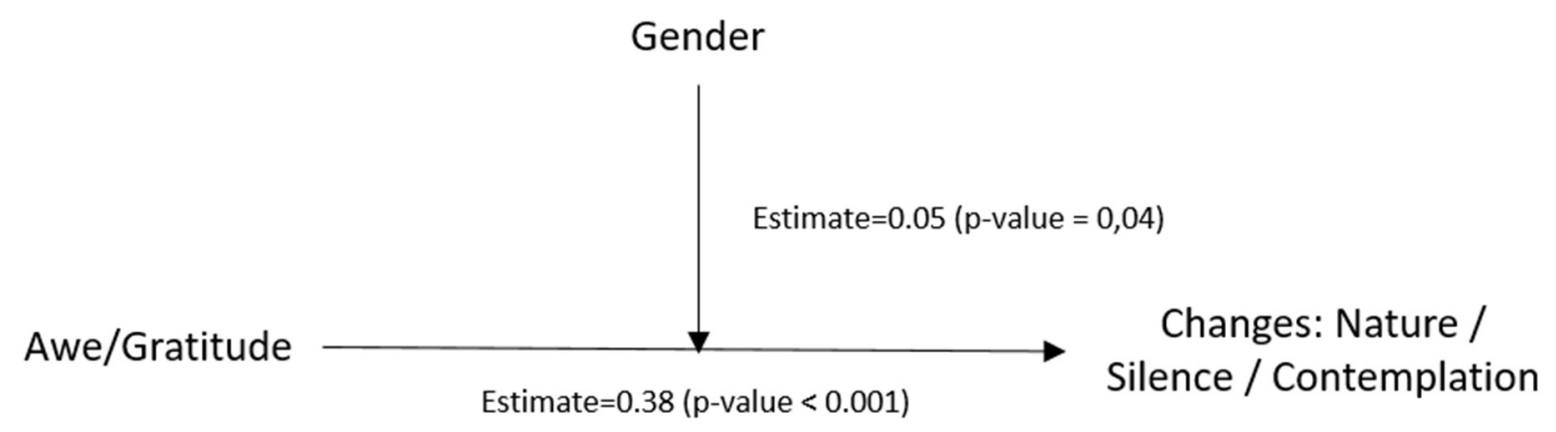

Figure 1: Moderation model for gender 


\section{Predictors of wellbeing}

To address which of the perceived changes would contribute to participants' wellbeing (as dependent variable), we performed a stepwise regression analysis with the perceived stressors, perceived changes, awe/gratitude as an indicator of spirituality, life satisfaction, and sociodemographic variables (gender, age and living in a monastery) as independent variables.

As shown in table 6, 9 variables would explain participants' wellbeing with good explanatory power $\left(\mathrm{R}^{2}=.51\right)$. Perceived burden ("stressors") and life satisfaction were the best predictors (explaining $46 \%$ of variance), while awe/gratitude, Nature / Silence / Contemplation, and low Reflection of life had a further impact. Age, gender, Digital media usage and Relations were of minor relevance and can be neglected. Living in a monastery, perceived changes in Spirituality, and perceived Restrictions were not among the significant variables in this model.

\section{Discussion}

We identified several topics of perceived changes during the Corona pandemic which were of relevance to the participants: 1) conscious experience of quiet times in live, mindful perceptions of nature and contemplative reflections (factor Nature / Silence / Contemplation), 2) interest in spiritual issues, religious trust, and more intense praying / meditation to connect with the Sacred (factor Spirituality), 3) more intense and closer relations with partner, family and friends as resources of social support (factor Relationships), 4) reflections about meaning in life and the lifetime one may have; these were, however, associated with the perception of loneliness (factor Reflection on life), 5) usage of digital media to stay connected with others and to be inspired by specific website content (factor Usage of Digital Media). Further, the 
topics of isolation and loss were of relevance, but not as an intrinsic part of the positive Perceptions of Change Questionnaire (which was found to have good internal consistency coefficients and a plausible factorial structure). Strongest changes were perceived for Relationships (particularly relationships in which one can feel safe and at home, and more intensive perceptions of relations with partner / family) and for Nature / Silence / Contemplation (particularly paying attention to what is really important in life, and perceiving nature more intensively), while Restrictions were perceived to a much lower extend. Interestingly, the positive changes were perceived significantly stronger by older persons and by those who relied on their faith as a resource (among them several religious brothers and sisters), while they perceived restrictions due to the pandemic less intensive. Older and retired persons may have more economic stability than younger persons who may fear for their workplace and financial-economic insecurity [14]. However, financial-economic insecurity was not a big issue in the investigated persons.

The perceived changes can be interpreted as ways to adapt with the outcomes of the COVID19 pandemic restrictions. These reactions might not necessarily result in higher wellbeing, because several were still dealing with these restrictions and may feel stressed. Perceived changes of attitudes and behaviors are rather a form of a reappraisal strategy (in terms of coping) to 'make the best' of a bad situation and thus to downregulate negative affect and arousal [24]. Interestingly, reappraisal seems to involve the lateral temporal cortex which is related to semantic and perceptual representation rather than emotional control [24]. The negative effects of the Corona pandemic restrictions might be cognitively interpreted as an opportunity to make new experiences which otherwise would not be 'learned', and thus as a chance for personally 'growth'. The pandemic-related 'transformation' or 'growth' (see $[8,9,10,11])$, however, was marginally too weakly only related to wellbeing or life satisfaction. More relevant were the associations of perceived changes with the perception of 
awe and subsequent feelings of gratitude. This variable was among the best predictors of persons' perceived changes during the lockdown. This perceptive aspect of spirituality is not restricted to religious persons but is perceived also by a-religious persons [18]. It can be seen as experience of "mindfulness towards the present moment" [19] and is also a "life orientation towards noticing and appreciating the positive in life" [25]. In this study, Nature / Silence / Contemplation was related best to awe/gratitude, which was its best predictor in the regression model. It is in fact among the relevant predictors of all positive. This means, timeout breaks might be needed to perceive things differently and to become more aware of all those aspects in life which were taken so-far for granted, as inherently 'available' at any time. However, the pandemic restrictions changed these 'automatisms' and one is now focused more on the uniqueness of specific situations, relations, and experiences of nature. In fact, the Corona lockdown coincided with the spring season, when the blooming of nature could be observed much more intensely, and thus perceiving "nature more intensively" and going “outdoors much more often" is comprehensible.

An important observation was that the intention to start working for a fairer future world (as a reaction towards the pandemic) was moderately related to the four main perceptions of change (and weakly only for Digital media usage, and not at all for perceived Restrictions). This means, the processes of reflection not only changed general perceptions, but also raised hope in terms of a better world in the future once the Corona pandemic will be over. This coincidences with a hope that people will pay more attention to each other and stick together, as both are moderately related $(\mathrm{r}=.41)$. This hope for a collaborative humankind was similarly related to the perceived changes, albeit weaker. Both items were primary an integral part of PCQ's factorial structure, but were finally not used due to a weak internal consistency of this 2-item factor. 
Interestingly, several changes were perceived stronger by male and female religious, living in monastic structures with their explicit contemplative lifestyle compared to other persons. Because of their lifestyle they might be sensitized (or trained) to perceive the Sacred in their life and to reflect on what is essential. One might argue that their wellbeing is higher because of their lifestyle, and this is true. Religious brothers' and sisters' wellbeing (16.6 \pm 4.6 vs 14.9 $\pm 5.2, \mathrm{p}<.0001 ;$ Mann-Whitney-U test) and also their Awe/Gratitude scores $(73.1 \pm 15.4 \mathrm{vs}$ $66.0 \pm 18.1 ; \mathrm{p}<.0001$, Mann-Whitney-U test) was in fact significantly higher compared to other persons. This would argue that the grade of wellbeing might be of relevance, whether one may have faith to rely on or not. However, we were unable to verify living in a monastery as a moderator of the link between awe/gratitude and wellbeing or perceived changes (data not shown). However, those with low wellbeing (30\%) perceived changes with respect to Relationships and Nature / Silence / Contemplation, but significantly lower compared to those with higher wellbeing, while they significantly reflected more on their life concerns compared to those with higher wellbeing. Further, Spirituality and Relationships scored significantly higher when persons felt well, compared to those with rather depressive scores of wellbeing. Also Persons with low wellbeing used digital media to connect with others and to overcome isolation, and this usage did not differ from others. This means, whether persons felt well or rather depressed during the pandemic has an influence what and how they perceive. When they have further faith as a resource to cope, all positive perceptions of change are stronger, and the negative restrictions were perceived less intensive. In the study of González-Sanguino et al. [14] spiritual wellbeing was found to be a protective factor against depression, anxiety and PTSD symptoms during the Corona pandemic, a finding which is not too surprising because most aspects of wellbeing are inversely related with reduced mental health indicators. Nevertheless, their data would underline the importance of this resource to cope during the Corona pandemic, too. 
How do these perceived changes contribute to a person's wellbeing during the pandemic? Regression analyses revealed that Nature / Silence / Contemplation would positively predict their wellbeing, while, however, Reflection of life was a negative predictor. This can be explained because it indicates that persons are more concerned about the meaning and purpose of their life and about the lifetime they have, and they perceive times of loneliness more intensely. These reflections have a negative connotation on the one hand, as it is related to anxiety and insecurity, and a positive connotation on the other hand, as it is positively related to awe/gratitude and meditation practices. Analyzing which of the so far tested variables would contribute to wellbeing revealed that first of all low perceived burden in terms of stressors and being satisfied with life in general were the best predictors among several others.

What are the consequences? Apart from general psychological support, perceiving nature, experiencing peaceful silence and wondering awe might be seen as resources to adapt during the pandemic. To support this, one might consider guided forest walks [26,27] to encourage feelings of inner peace and stress-relief, also with the possibility of virtual walks for groups at risk. Further, mindfulness based meditation to relieve stress, reduce anxiety and depressive states, and to encourage conscious interactions with others could prove useful $[28,29]$, either as an individual practice at home and or in a group setting to avoid feelings of isolation and loneliness. Even web and app based mindfulness approaches seem to be effective [30,31]. Important for most persons during the time of restrictions were concrete contacts with others on distance. Here, digital media resources proved their relevance, as this study has shown. Social media may facilitate visual communication on distance, while specific websites may provide content to inspire and stimulate others and thus allow the impression of participation. Others used such websites to attend digital services of worship, which may be a source of hold and hope for religious people. In fact, several relied on their faith as a resource to cope, 
while others do not have access to this source. A vital faith cannot be prescribed, but one could be made sensible for spiritual practices (i.e., meditation, prayer, distinct rituals) and train awareness of the uniqueness of the moment (referring to mindful awareness, conscious interactions and feelings of awe in specific situations). Therefore, retreats in monastic contexts could be an option to consolidate faith or to make new experience with a different lifestyle. Such contacts would also facilitate talks with pastoral professionals when phases of religious struggles $[32,33]$ or spiritual dryness [34,35] may affect a person's emotional and spiritual wellbeing. Further consequences which could be drawn from these findings remain to be discussed and tested in the next waves of the COVID-1 pandemic.

\section{Limitations}

The study was performed as an online survey with a snowball sampling method and thus was not easily available for persons lacking internet access. We thus do not assume that the findings are representative for all German societies as the sampling strategy might have favored persons from academic contexts. The proportion of male and female catholic religious is probably higher than in a representative sample; however, it was our aim to have them in the sample as a contrasting group compared to persons with other live styles. Further, the cross-sectional design does nether allow any causal conclusions.

The number of the persons with COVID-19 infections in this sample (1.1\%) seems to be a bit higher compared to the general German population in Germany within the time frame $(0.2 \%)$.

Why the non-responders did not continue the online questionnaire is unclear. Comparing the non-responders with those who completed the survey did not show significant differences with respect to gender, age, lack of religious affiliations or COVID-19 infection testing. 
Further, we have not knowledge about pre-existing mental health conditions of enrolled persons that may have impact the responses to the survey. We have decided to not ask for mental or physical diseases to increase willingness to participate.

\section{Conclusions}

During the first phase of the COVID-19 pandemic people tried to find ways to adapt to the outcomes of the restrictions. The perceived changes of attitudes and behaviors can be interpreted in terms of a reappraisal strategy. They can be measured with the extended version of the Perceived Changes Questionnaire (PCQ) which was found to have good quality indices and plausible factor structure and is currently applied also in other cultural and religious contexts.

These observed perceptions of change contribute to persons' wellbeing only to some extend and represent an independent quality of relevance in their life. Particularly perceived Reflection of life can be a hint of reduced life satisfaction, anxiety and loneliness and indicates need for special attention and support. It was crucial that most of these perceived changes were related to the ability to stop and perceive wondering awe with subsequent feelings of gratitude. These abilities could be fostered as they may provide a further resource to cope and find stability during difficult times. Now in October 2020, the second wave of the COVID-19 pandemic hits most countries with strong increases of infected persons. Whether the perceived changes of attitudes and behaviors really have an enduring impact that contributes to mental stability and posttraumatic growth remains to be shown remains to be during the next waves of the pandemic. 


\section{References}

1. Zhai P, Ding Y, Wu X, Long J, Zhong Y, Li Y. The epidemiology, diagnosis and treatment of COVID-19. Int J Antimicrob Agents. 2020;55(5):105955. doi:10.1016/j.ijantimicag.2020.105955

2. Shi Y, Wang G, Cai XP, et al. An overview of COVID-19. J Zhejiang Univ Sci B. 2020;21(5):343-360. doi:10.1631/jzus.B2000083

3. Gosain R, Abdou Y, Singh A, Rana N, Puzanov I, Ernstoff MS. COVID-19 and Cancer: a Comprehensive Review. Curr Oncol Rep. 2020;22(5):53. doi:10.1007/s11912-020-00934-7

4. Büntzel J, Klein M, Keinki C, Walter S, Büntzel J, Hübner J. Oncology services in corona times: a flash interview among German cancer patients and their physicians. J Cancer Res Clin Oncol. 2020: 1-3. doi:10.1007/s00432-020-03249-z

5. Shader RI. COVID-19 and Depression. Clin Ther. 2020;42(6):962-963. doi:10.1016/j.clinthera.2020.04.010

6. Carthaus A: Coronavirus and mental health: 'We are not made for social isolation. Deutsche Welle. April 1, 2020. https://www.dw.com/en/coronavirus-and-mentalhealth-we-are-not-made-for-social-isolation/a-52971173. Last access: October 27, 2020

7. Büssing A, Hübner J, Walter S, Gießler W, Büntzel J: Tumor patients' perceived changes of specific attitudes, perceptions and behaviors due to the Corona pandemic and its relation to reduced wellbeing. Frontiers in Psychiatry 2020;11:574314. doi: $10.3389 /$ fpsyt. 2020.574314

8. Paloutzian RF: Religious conversion and spiritual transformation: A meaning-system analysis. In Raymond F. Paloutzian \& Crystal L. Park (Eds.), Handbook of the psychology of religion and spirituality. New York: Guilford; 2005, pp. 331-347. 
9. Pargament KI. The meaning of spiritual transformation. In Joan D. Koss-Chioino \& Philip Hefner (Eds.), Spiritual transformation and healing: Anthropological, theological, neuroscientific, and clinical perspectives. Walnut Creek, CA: AltaMira Press; 2006, pp. 10-39.

10. Ai AL, Hall D, Pargament K, Tice TN. Posttraumatic growth in patients who survived cardiac surgery: the predictive and mediating roles of faith-based factors. J Behav Med. 2013;36:186-198.

11. Tedeschi RG, Shakespeare-Finch J, Taku K, Calhoun LG: Posttraumatic Growth. Theory, Research, and Applications. Taylor and Francis; 2018.

12. Kremer H, Ironson G: Everything Changed: Spiritual Transformation in People With HIV. Int J Psychiatry Med. 2009;39:243-262.

13. Ironson G, Kremer H: Spiritual transformation, psychological well-being, health, and survival in people with HIV. Int J Psychiatry Med. 2009;39:263-281.

14. González-Sanguino C, Ausín B, Castellanos MÁ, et al. Mental health consequences during the initial stage of the 2020 Coronavirus pandemic (COVID-19) in Spain. Brain Behav Immun. 2020;87:172-176. doi:10.1016/j.bbi.2020.05.040

15. Pargament K. I., Smith B. W., Koenig H. G., Perez L: Patterns of positive and negative religious coping with major life stressors. Journal for the Scientific Study of Religion. 1998;374:710-724.

16. Ano GG, Vasconcelles EB. Religious coping and psychological adjustment to stress: a meta-analysis. J Clin Psychol. 2005;61:461-480.

17. Bryant-Davis T, Wong EC. Faith to move mountains: religious coping, spirituality, and interpersonal trauma recovery. Am Psychol. 2013;68:675-684.

18. Büssing A, Rechia DR, Baumann K: Validation of the Awe/Gratitude Questionnaire and Its Association with Disposition of Gratefulness. Religions. 2018;9:117. doi: 10.3390/re19040117. 
19. Büssing A: Ehrfurcht/Dankbarkeit als säkulare Form der Spiritualität bei jungen Erwachsenen und Ordens-Christen. Spiritual Care. 2020;9:3-11

20. Bech P, Olsen LR, Kjoller M, Rasmussen NK: Measuring well-being rather than the absence of distress symptoms: A comparison of the SF-36 mental health subscale and the WHO-Five well-being scale. International Journal of Methods in Psychiatric Research. 2013;12:85-91.

21. Topp CW, Østergaard SD, Søndergaard S, Bech P. The WHO-5 Well-Being Index: A Systematic Review of the Literature. Psychother Psychosom 2015;84:167-176.

22. Büssing A, Fischer J, Haller A, Heusser P, Ostermann T, Matthiessen PF: Validation of the brief multidimensional life satisfaction scale in patients with chronic diseases. European Journal of Medicine Research. 2009;14:171-177.

23. Büssing A, Recchia DR, Baumann K: The Reliance on God's Help Scale as a Measure of Religious Trust - A Summary of Findings. Religions 2015;6:1358-1367.

24. Buhle JT, Silvers JA, Wager TD, Lopez R, Onyemekwu C, Kober H, Weber J, Ochsner KN: Cognitive reappraisal of emotion: a meta-analysis of human neuroimaging studies. Cerebral Cortex. 2014;24:2981-2990.

25. Büssing A, Wirth AG, Reiser F, Zahn A, Humbroich K, Gerbershagen K, Schimrigk S, Haupts S, Hvidt NC, Baumann K: Experience of gratitude, awe and beauty in life among patients with multiple sclerosis and psychiatric disorders. Health and Quality of Life Outcomes. 2014;12:63

26. Park BJ, Tsunetsugu Y, Kasetani T, et al. Physiological effects of Shinrin-yoku (taking in the atmosphere of the forest)--using salivary cortisol and cerebral activity as indicators. J Physiol Anthropol. 2007;26(2):123-128. doi:10.2114/jpa2.26.123

27. Richardson EA, Pearce J, Mitchell R, Kingham S: Role of physical activity in the relationship between urban green space and health. Public Health. 2013;127:318-324. 28. Goyal M, Singh S, Sibinga EM, Gould NF, Rowland-Seymour A, Sharma R, Berger 
Z, Sleicher D, Maron DD, Shihab HM, Ranasinghe PD, Linn S, Saha S, Bass EB, Haythornthwaite JA: Meditation programs for psychological stress and well-being: a systematic review and meta-analysis. JAMA Intern Med. 2014;174(3):357-368.

29. Simkin DR, Black NB. Meditation and mindfulness in clinical practice. Child Adolesc Psychiatr Clin N Am. 2014;23(3):487-534. doi:10.1016/j.chc.2014.03.002

30. Toivonen KI, Zernicke K, Carlson LE. Web-Based Mindfulness Interventions for People With Physical Health Conditions: Systematic Review. J Med Internet Res. 2017;19:e303

31. Huberty J, Green J, Glissmann C, Larkey L, Puzia M, Lee C: Efficacy of the Mindfulness Meditation Mobile App "Calm" to Reduce Stress Among College Students: Randomized Controlled Trial. JMIR Mhealth Uhealth. 2019;7(6):e14273. doi:10.2196/14273

32. Exline JJ, Rose ED: Religious and spiritual struggles. In R.F. Paloutzian \& C.L. Park (Eds.), Handbook of the psychology of religion and spirituality (2nd ed.). New York: Guilford; 2013. pp. 380-398.

33. Exline JJ, Grubbs JB, Homolka SJ. Seeing God as cruel vs. distant: Links with divine struggles involving anger, doubt, and fear of God's disapproval. International Journal for the Psychology of Religion. 2015;25:29-41.

34. Büssing A, Günther A, Baumann K, Frick E, Jacobs C. Spiritual dryness as a measure of a specific spiritual crisis in Catholic priests: associations with symptoms of burnout and distress. Evidence-Based Complementary and Alternative Medicine. 2013;246797. doi:10.1155/2013/246797.

35. Büssing A, Winter S, Baumann K. Perception of Religious Brothers and Sisters and Lay Persons That Prayers Go Unanswered Is a Matter of Perceived Distance from God. Religions 2020b;11:178. doi:10.3390/rel11040178. 


\section{Acknowledgements}

We highly appreciate the support of all friends and colleagues who have forwarded the questionnaire, and to all who responded to the questionnaire.

\section{Funding}

This study had no external funding.

\section{Contributions}

$\mathrm{AB}$ designed the study and set up the online survey. The PCQ was designed by AB with further input by $\mathrm{TD}$ and $\mathrm{RH}$. TD, $\mathrm{RH}$ and $\mathrm{AB}$ initiated the sampling processes. $\mathrm{AB}$ undertook statistical analyses, DRR performed the moderator analyses. AB wrote the first draft of the paper, and all authors provided feedback. All authors approved the final manuscript.

\section{Ethics approval and consent to participate}

Healthy participants were responding to an anonym online survey and were recruited on voluntary basis. Participants were assured confidentially and were informed about the purpose of the study and data protection information at the starting page of the online survey. By filling in the anonymous questionnaire, interested persons consented to participate. Neither concrete identifying personal details nor IP addresses were recorded to guarantee anonymity

\section{Competing interests}

The authors declare that they have no competing interests. 


\section{Availability of data and materials}

According to the data protection regulations, the data set cannot be made publicly available.

Data are however available from the authors upon reasonable request. 
Table 1: Sociodemographic data of participants $(\mathrm{N}=1,277)$

\begin{tabular}{|c|c|c|c|c|}
\hline & $\mathrm{n}$ & $\begin{array}{c}\% \% \\
\text { of responders } \\
\end{array}$ & $\begin{array}{l}\text { mean } \\
\pm \mathrm{SD}\end{array}$ & range \\
\hline \multicolumn{5}{|l|}{ Gender } \\
\hline Women & 859 & 67.5 & & \\
\hline men & 414 & 32.5 & & \\
\hline Age (years) & 1261 & & $50.9 \pm 14.9$ & $15-92$ \\
\hline \multicolumn{5}{|l|}{ Living conditions } \\
\hline Family household & 534 & 41.8 & & \\
\hline Shared house & 131 & 10.3 & & \\
\hline Single & 252 & 19.7 & & \\
\hline Retirement home & 1 & 0.1 & & \\
\hline Monastery / Community & 162 & 12.7 & & \\
\hline \multicolumn{5}{|l|}{ Profession } \\
\hline Administration & 181 & 14.2 & & \\
\hline Economy & 134 & 10.5 & & \\
\hline Education & 178 & 13.0 & & \\
\hline Medicine/Health & 234 & 17.0 & & \\
\hline Church & 314 & 22.9 & & \\
\hline other & 391 & 28.5 & & \\
\hline \multicolumn{5}{|l|}{ Corona tested } \\
\hline Positively tested & 10 & 0.8 & & \\
\hline Negatively tested & 103 & 8.1 & & \\
\hline No testing & 1164 & 91.2 & & \\
\hline $\begin{array}{l}\text { Irritated or unsettled by different statements } \\
\text { about the danger and the course of the corona } \\
\text { infection in the public media }\end{array}$ & 1277 & & $1.4 \pm 0.9$ & $0-3$ \\
\hline Not at all & 220 & 17.2 & & \\
\hline A little & 493 & 38.6 & & \\
\hline somewhat & 389 & 30.5 & & \\
\hline very much & 175 & 13.7 & & \\
\hline \multicolumn{5}{|l|}{ Religious affiliation } \\
\hline Catholics & 740 & 57.9 & & \\
\hline Protestant & 235 & 18.3 & & \\
\hline Other & 72 & 5.7 & & \\
\hline None & 241 & 18.9 & & \\
\hline \multicolumn{5}{|l|}{ Faith as strong hold in difficult times } \\
\hline Disagreement & 271 & 21.5 & & \\
\hline Undecided & 344 & 27.2 & & \\
\hline Agreement & 648 & 51.3 & & \\
\hline Awe / Gratitude (GrAw-7) & 1267 & & $66.8 \pm 17.9$ & $0-100$ \\
\hline Meditation & & & Meditation & \\
\hline Never & 407 & 33.9 & was practices & \\
\hline At least once per month & 176 & 14.6 & quite often & \\
\hline At least once per week & 257 & 21.4 & $30 \%$ & \\
\hline At least once per day & 362 & 30.1 & & \\
\hline Praying & & & Praying was & \\
\hline Never & 321 & 26.8 & often used & \\
\hline At least once per month & 121 & 10.1 & quite often & \\
\hline At least once per week & 175 & 14.6 & $49 \%$ & \\
\hline At least once per day & 581 & 48.5 & & \\
\hline Mood lifting drugs & & & Mood lifting & \\
\hline Never & 1129 & 95.4 & drugs were & \\
\hline At least once per month & 10 & 0.8 & & \\
\hline
\end{tabular}




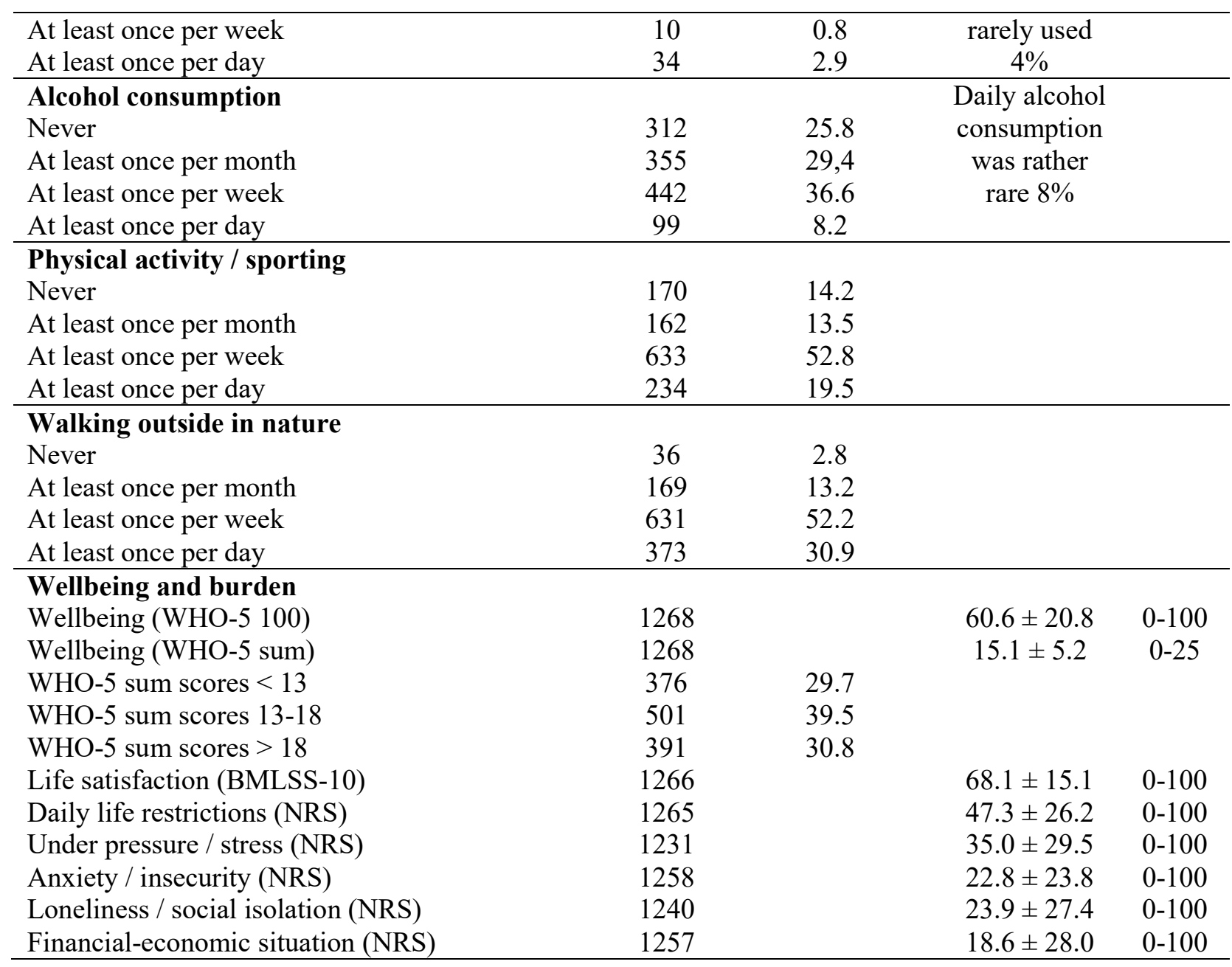


Table 2: Factor and reliability analyses (24 items)

\begin{tabular}{|c|c|c|c|c|c|c|c|c|c|c|c|}
\hline \multirow[b]{2}{*}{$\begin{array}{l}\text { Intended } \\
\text { Topic }\end{array}$} & \multirow[b]{2}{*}{ Items } & \multirow[b]{2}{*}{$\begin{array}{l}\text { Mean } \\
\text { value }\end{array}$} & \multirow[b]{2}{*}{ SD } & \multirow{2}{*}{$\begin{array}{l}\text { Difficul } \\
\text { ty index } \\
(2.33 / 4 \\
=0.58) \\
\end{array}$} & \multirow{2}{*}{$\begin{array}{l}\text { Corrected } \\
\text { item - } \\
\text { scale } \\
\text { correlation }\end{array}$} & \multirow{2}{*}{$\begin{array}{l}\text { Cronbach's } \\
\text { alpha } \\
\text { if item deleted } \\
(\text { alpha }=.908)\end{array}$} & \multicolumn{5}{|c|}{ Factor loading } \\
\hline & & & & & & & 1 & 2 & 3 & 4 & 5 \\
\hline & $\begin{array}{l}\text { Eigenvalue } \\
\text { Cronbach's alpha }\end{array}$ & & & & & & $\begin{array}{l}7.6 \\
.868\end{array}$ & $\begin{array}{l}2.3 \\
.827\end{array}$ & $\begin{array}{l}1.7 \\
.800\end{array}$ & $\begin{array}{l}1.4 \\
.744\end{array}$ & $\begin{array}{l}1.3 \\
.742\end{array}$ \\
\hline Silence & $\begin{array}{l}\text { Factor 1: Nature / Silence / } \\
\text { Contemplation } \\
\text { c12 I consciously take more time for } \\
\text { silence. }\end{array}$ & 2.15 & 1.17 & 0.54 & .671 & .901 & .724 & .382 & & & \\
\hline Mindfulness & c11 I perceive nature more intensely. & 2.63 & 1.10 & 0.66 & .632 & .902 & .710 & & & & \\
\hline Mindfulness & c10 I go outdoors much more often & 2.61 & 1.12 & 0.65 & .497 & .904 & .678 & & & & \\
\hline Mindfulness & $\begin{array}{l}\text { c8 I come to deal more with myself } \\
\text { again }\end{array}$ & 2.44 & 1.06 & 0.61 & .547 & .903 & .663 & & & & \\
\hline Silence & c13 I enjoy quiet times of reflection. & 2.29 & 1.21 & 0.57 & .663 & .901 & .649 & .439 & & & \\
\hline Mindfulness & $\begin{array}{l}\text { c9 I pay more attention to what's really } \\
\text { important in life }\end{array}$ & 2.72 & 1.00 & 0.68 & .648 & .902 & 615 & & .362 & & \\
\hline Mindfulness & c7 I'm more relaxed than before & 2.00 & 1.04 & 0.50 & .344 & .907 & .579 & & & -.302 & \\
\hline & Factor 2: Spirituality & & & & & & & & & & \\
\hline Spirituality & $\begin{array}{l}\text { c32 I have confidence in a higher power } \\
\text { that supports me }\end{array}$ & 2.69 & 1.39 & 0.67 & .514 & .904 & & .791 & & & \\
\hline Spirituality & $\begin{array}{l}\text { c31 I deal more with spiritual / religious } \\
\text { questions }\end{array}$ & 1.79 & 1.22 & 0.45 & .622 & .902 & & .755 & & & \\
\hline Spirituality & $\begin{array}{l}\text { c20 I'm more interested in spiritual / } \\
\text { religious issues }\end{array}$ & 1.77 & 1.19 & 0.44 & .649 & .901 & & .733 & & & \\
\hline Spirituality & c29 I pray / meditate more than before & 1.70 & 1.23 & 0.43 & .612 & .902 & .322 & .692 & & & \\
\hline Spirituality & $\begin{array}{l}\text { c22 I took advantage of digital worship } \\
\text { services }\end{array}$ & 1.54 & 1.58 & 0.39 & .340 & .909 & & .643 & & & \\
\hline Connectedness & $\begin{array}{l}\text { Factor 3: Relationships } \\
\text { c1 I perceive the relationship with my } \\
\text { partner / family more intensely }\end{array}$ & 2.72 & 1.00 & 0.68 & .431 & .906 & & & .775 & & \\
\hline
\end{tabular}




\begin{tabular}{|c|c|c|c|c|c|c|c|c|c|c|c|}
\hline Connectedness & $\begin{array}{l}\text { c4 I feel closer to the people in my } \\
\text { household }\end{array}$ & 2.69 & 1.07 & 0.67 & .417 & .906 & & & .748 & & \\
\hline Connectedness & $\begin{array}{l}\text { c3 I take more time for my family / } \\
\text { friends }\end{array}$ & 2.51 & 1.03 & 0.63 & .508 & .904 & & & .694 & & \\
\hline Connectedness & $\begin{array}{l}\text { c5 relationships have become important } \\
\text { to me in which I can feel safe and at } \\
\text { home. }\end{array}$ & 2.89 & 0.98 & 0.72 & .571 & .903 & & & .654 & & \\
\hline Connectedness & $\begin{array}{l}\text { c2 I perceive the relationships with my } \\
\text { friends more intensely }\end{array}$ & 2.34 & 1.04 & 0.59 & .443 & .905 & & & .560 & & \\
\hline Mindfulness & c6 I try to be more friendly with others & 2.61 & 0.93 & & .526 & .904 & .326 & & .508 & & \\
\hline Meaning & $\begin{array}{l}\text { Factor 4: Reflection on life } \\
\text { c24 I'm more concerned about the } \\
\text { meaning and purpose of my life }\end{array}$ & 2.29 & 1.21 & 0.57 & & & & & & .793 & \\
\hline Meaning & $\begin{array}{l}\text { c23 I'm more concerned about the } \\
\text { lifetime that I have }\end{array}$ & 2.23 & 1.24 & 0.56 & & & & & & .784 & \\
\hline Isolation & $\begin{array}{l}\text { c14 I perceive times of loneliness more } \\
\text { intensely }\end{array}$ & 2.05 & 1.26 & & .413 & .906 & .322 & & & .529 & \\
\hline Connectedness & $\begin{array}{l}\text { Factor 5: Digital media usage } \\
\text { c19 I use many internet offers that let } \\
\text { me share in the world }\end{array}$ & 2.29 & 1.20 & 0.57 & .372 & .907 & & & & & .881 \\
\hline Connectedness & $\begin{array}{l}\text { c18 I am connected to friends via digital } \\
\text { media. }\end{array}$ & 2.76 & 1.05 & 0.69 & .345 & .907 & & & & & .778 \\
\hline \multirow[t]{2}{*}{ Spirituality } & $\begin{array}{l}\text { c21 I use more and more websites that } \\
\text { inspire and stimulate me. }\end{array}$ & 1.91 & 1.20 & 0.48 & .509 & .904 & & .405 & & & .637 \\
\hline & Deleted Items & & & & & & & & & & \\
\hline Isolation & c15 I feel cut off from life. & 1.15 & 1.25 & & & & & & & & \\
\hline Isolation & c16 I feel restricted in my freedom & 1.82 & 1.33 & & & & & & & & \\
\hline Isolation & c17 I lack social contacts. & 2.13 & 1.34 & & & & & & & & \\
\hline Hope & $\begin{array}{l}\text { c } 25 \text { I have the hope that we } \\
\text { ('afterwards') as global mankind will } \\
\text { pay more attention to each other and } \\
\text { stick together. }\end{array}$ & 2.47 & 1.21 & & & & & & & & \\
\hline
\end{tabular}


c26 I would like to start working to

ensure that the world becomes fairer in

the future.

Loss c27 I find that our society is falling

apart more and more

$2.54 \quad 1.01$

c28 I rather fear for the future.

$1.78 \quad 1.13$

Loss

c30 I lost my belief.

$0.50 \quad 0.86$

Extraction method: Principle component analysis (Varimax rotation with Kaiser normalization). Rotation is converged in 6 iterations; the 6 factors explain $61 \%$ of variance 
Table 3: Strength of perceived changes within different sub-groups

\begin{tabular}{|c|c|c|c|c|c|c|c|}
\hline & \multicolumn{6}{|c|}{ Perceived changes } \\
\hline & & \multirow{2}{*}{$\begin{array}{c}\text { Nature / Silence / } \\
\text { Contemplation }\end{array}$} & \multirow{2}{*}{$\frac{\text { Spirituality }}{47.66}$} & \multirow{2}{*}{$\frac{\text { Relationships }}{65.74}$} & $\begin{array}{l}\text { Reflection } \\
\text { on life }\end{array}$ & \multirow{2}{*}{$\begin{array}{c}\begin{array}{c}\text { Digital } \\
\text { media usage }\end{array} \\
57.99\end{array}$} & \multirow{2}{*}{$\frac{\text { Restrictions }}{42.54}$} \\
\hline & & & & & 55.06 & & \\
\hline & & 20.50 & 25.95 & 18.26 & 25.42 & 23.57 & 27.40 \\
\hline \multicolumn{8}{|l|}{ Gender } \\
\hline \multirow[t]{2}{*}{ female } & Mean & 62.15 & 48.92 & 66.65 & 57.07 & 58.32 & 42.45 \\
\hline & SD & 20.79 & 26.07 & 18.29 & 25.27 & 24.38 & 27.58 \\
\hline \multirow[t]{2}{*}{ male } & Mean & 56.55 & 45.20 & 63.86 & 50.93 & 57.30 & 42.57 \\
\hline & SD & 19.41 & 25.57 & 18.10 & 25.28 & 21.93 & 26.86 \\
\hline F value & & 20.26 & 5.51 & 6.23 & 15.71 & 0.49 & 0.01 \\
\hline $\mathrm{p}$ value & & $<.0001$ & .019 & .013 & $<.0001$ & n.s. & n.s. \\
\hline \multicolumn{8}{|l|}{ Age cohorts } \\
\hline \multirow[t]{2}{*}{$<30$ years } & Mean & 54.27 & 30.35 & 63.70 & 52.59 & 57.50 & 51.99 \\
\hline & SD & 19.37 & 24.50 & 16.79 & 25.00 & 23.64 & 27.65 \\
\hline \multirow[t]{2}{*}{$30-40$ years } & Mean & 52.29 & 35.93 & 61.60 & 45.20 & 57.82 & 43.29 \\
\hline & SD & 20.97 & 27.10 & 19.20 & 26.60 & 21.69 & 27.51 \\
\hline \multirow[t]{2}{*}{$41-50$ years } & Mean & 57.98 & 46.89 & 64.13 & 51.04 & 57.41 & 44.26 \\
\hline & SD & 21.09 & 25.27 & 18.02 & 26.15 & 24.24 & 28.81 \\
\hline \multirow[t]{2}{*}{$51-60$ years } & Mean & 61.92 & 51.71 & 66.97 & 55.65 & 57.70 & 40.64 \\
\hline & SD & 20.19 & 22.60 & 18.34 & 24.47 & 24.02 & 25.68 \\
\hline \multirow[t]{2}{*}{$61-70$ years } & Mean & 63.70 & 51.89 & 66.26 & 58.43 & 57.93 & 40.36 \\
\hline & SD & 18.85 & 22.92 & 17.64 & 23.79 & 22.18 & 28.34 \\
\hline \multirow[t]{2}{*}{$>70$ years } & Mean & 70.54 & 65.14 & 72.28 & 70.54 & 60.82 & 33.96 \\
\hline & SD & 17.80 & 26.43 & 18.62 & 22.20 & 26.09 & 23.78 \\
\hline F value & & 14.93 & 35.84 & 5.18 & 14.51 & 0.33 & 6.51 \\
\hline $\mathrm{p}$ value & & $<.0001$ & $<.0001$ & $<.0001$ & $<.0001$ & n.s. & $<.0001$ \\
\hline \multicolumn{8}{|l|}{ Religious } \\
\hline \multirow[t]{2}{*}{ Living in Monastery } & Mean & 65.52 & 63.37 & 66.86 & 60.68 & 61.49 & 35.62 \\
\hline & SD & 21.09 & 21.41 & 18.63 & 25.30 & 25.84 & 25.89 \\
\hline \multirow[t]{2}{*}{ All other } & Mean & 59.51 & 45.36 & 65.58 & 54.25 & 57.50 & 43.52 \\
\hline & SD & 20.31 & 25.77 & 18.21 & 25.34 & 23.20 & 27.48 \\
\hline F value & & 11.73 & 68.74 & 0.65 & 8.60 & 3.76 & 11.07 \\
\hline $\mathrm{p}$ value & & .001 & $<.0001$ & n.s. & .003 & .053 & .001 \\
\hline Faith as a strong hold & & & & & & & \\
\hline does not apply & Mean & 52.72 & 19.50 & 60.02 & 46.94 & 54.22 & 43.82 \\
\hline & SD & 22.37 & 22.88 & 20.20 & 28.18 & 24.03 & 28.44 \\
\hline partly & Mean & 58.30 & 44.05 & 65.01 & 55.68 & 56.95 & 47.32 \\
\hline & SD & 18,76 & 19.22 & 16.00 & 23.82 & 22.11 & 26.86 \\
\hline applies & Mean & 64.45 & 60.91 & 68.62 & 58.24 & 60.28 & 39.81 \\
\hline & SD & 19.63 & 19.77 & 17.79 & 24.31 & 24.04 & 26.84 \\
\hline F value & & 33.13 & 377.52 & 21.22 & 18.40 & 6.46 & 8.43 \\
\hline $\mathrm{p}$ value & & $<.0001$ & $<.0001$ & $<.0001$ & $<.0001$ & .002 & $<.0001$ \\
\hline Wellbeing (WHO-5) & & & & & & & \\
\hline Scores $<13$ & Mean & 55.42 & 45.05 & 63.26 & 60.41 & 56.80 & 57.50 \\
\hline & SD & 19.51 & 24.72 & 16.68 & 24.56 & 23.09 & 27.04 \\
\hline Scores 13-18 & Mean & 59.16 & 46.36 & 65.56 & 53.08 & 58.08 & 41.14 \\
\hline & SD & 19.70 & 25.30 & 18.32 & 25.22 & 22.69 & 25.12 \\
\hline Scores $>18$ & Mean & 66.08 & 51.67 & 68.38 & 52.66 & 59.06 & 30.06 \\
\hline & SD & 20.97 & 27.38 & 19.16 & 25.76 & 25.09 & 23.64 \\
\hline
\end{tabular}


n.s. 
Table 4: Correlations between perceived changes and external variables

\begin{tabular}{|c|c|c|c|c|c|c|}
\hline & \multicolumn{6}{|c|}{ Perceived changes } \\
\hline & $\begin{array}{l}\text { Nature / Silence } \\
\text { / Contemplation }\end{array}$ & Spirituality & Relationships & $\begin{array}{l}\text { Reflection } \\
\text { of live }\end{array}$ & $\begin{array}{c}\text { Digital } \\
\text { media } \\
\text { usage }\end{array}$ & Restrictions \\
\hline $\begin{array}{l}\text { Perceived Changes } \\
\text { Nature / Silence / Contemplation }\end{array}$ & 1.000 & & & & & \\
\hline Spirituality & $.476 * *$ & 1.000 & & & & \\
\hline Relationships & $.544 * *$ & $.320 * *$ & 1.000 & & & \\
\hline Reflection on life & $.467 * *$ & $.449 * *$ & $.344 * *$ & 1.000 & & \\
\hline Digital media usage & $.283 * *$ & $.385 * *$ & $.214 * *$ & $.284 * *$ & 1.000 & \\
\hline Perceived Restrictions & $-.152 * *$ & -.043 & $-.112 * *$ & $.169 * *$ & $.060 *$ & 1.000 \\
\hline $\begin{array}{l}\text { Perceived changes: Hope for } \\
\text { changes } \\
\text { c25 hope that we ('afterwards') as } \\
\text { global mankind will pay more } \\
\text { attention to each other and stick } \\
\text { together. }\end{array}$ & $.283 * *$ & $.250 * *$ & $.247 * *$ & $.252 * *$ & $.205^{* *}$ & -.065 \\
\hline $\begin{array}{l}\text { c } 26 \text { work to ensure that the world } \\
\text { becomes fairer in the future }\end{array}$ & $.354 * *$ & $.327 * *$ & $.318 * *$ & $.335 * *$ & $.218 * *$ & -.016 \\
\hline Perceived burden ("Stressors") & $-.116^{* *}$ & -.025 & -.011 & $.213 * *$ & $.093^{* *}$ & $.592 * *$ \\
\hline Restricted in daily life (NRS) & $-.120 * *$ & -.019 & -.020 & $.122 * *$ & $.098 * *$ & $.552 * *$ \\
\hline Under pressure / stressed (NRS) & $-.159 * *$ & -.038 & -.011 & $.165 * *$ & .068 & $.452 * *$ \\
\hline Anxiety / Insecurity (NRS) & -.013 & .069 & .059 & $.266^{* *}$ & $.094 * *$ & $.354 * *$ \\
\hline Loneliness / social isolation (NRS) & -.072 & -.020 & -.049 & $.197 * *$ & $.099 * *$ & $.630 * *$ \\
\hline Financial-economic situation (NRS) & .007 & -.046 & -.008 & $.123 * *$ & .022 & $.235 * *$ \\
\hline Life satisfaction / Wellbeing & & & & & & \\
\hline Wellbeing (WHO5) & $.225 * *$ & $.098 * *$ & $.136^{* *}$ & $-.133^{* *}$ & .049 & $-.430 * *$ \\
\hline Life satisfaction (BMLSS-10) & $.124 * *$ & .014 & $.204 * *$ & $-.214^{* *}$ & .001 & $-.390 * *$ \\
\hline Spirituality & & & & & & \\
\hline Faith as strong hold & $.223 * *$ & $.592 * *$ & $.181^{* *}$ & $.151^{* *}$ & $.112^{* *}$ & $-.088^{* *}$ \\
\hline Awe/Gratitude (GrAw-7) & $.403 * *$ & $.388 * *$ & $.331 * *$ & $.260 * *$ & $.151^{* *}$ & $-.163 * *$ \\
\hline Meditation & $.372 * *$ & $.461 * *$ & $.177^{* *}$ & $.237 * *$ & $.148^{* *}$ & $-.094 * *$ \\
\hline Praying & $.209 * *$ & $.636 * *$ & $.142 * *$ & $.195 * *$ & $.142 * *$ & -.072 \\
\hline Health Behavior & & & & & & \\
\hline Alcohol consumption & -.029 & $-.094 * *$ & -.002 & -.045 & .008 & .022 \\
\hline Physical activity / sporting & $.179 * *$ & -.036 & $.096^{* *}$ & .053 & .022 & .002 \\
\hline Walking outside in nature & $.267 * *$ & $.120 * *$ & $.146^{* *}$ & $.091 * *$ & $.086 * *$ & -.028 \\
\hline Relaxing drugs & -.025 & .007 & .006 & $.080 * *$ & -.002 & $.121 * *$ \\
\hline
\end{tabular}

$* * \mathrm{p}<0.001$ (Spearman rho); moderate to strong correlations were highlighted (bold) 
Table 5: Predictors of perceived changes (stepwise regression analyses)

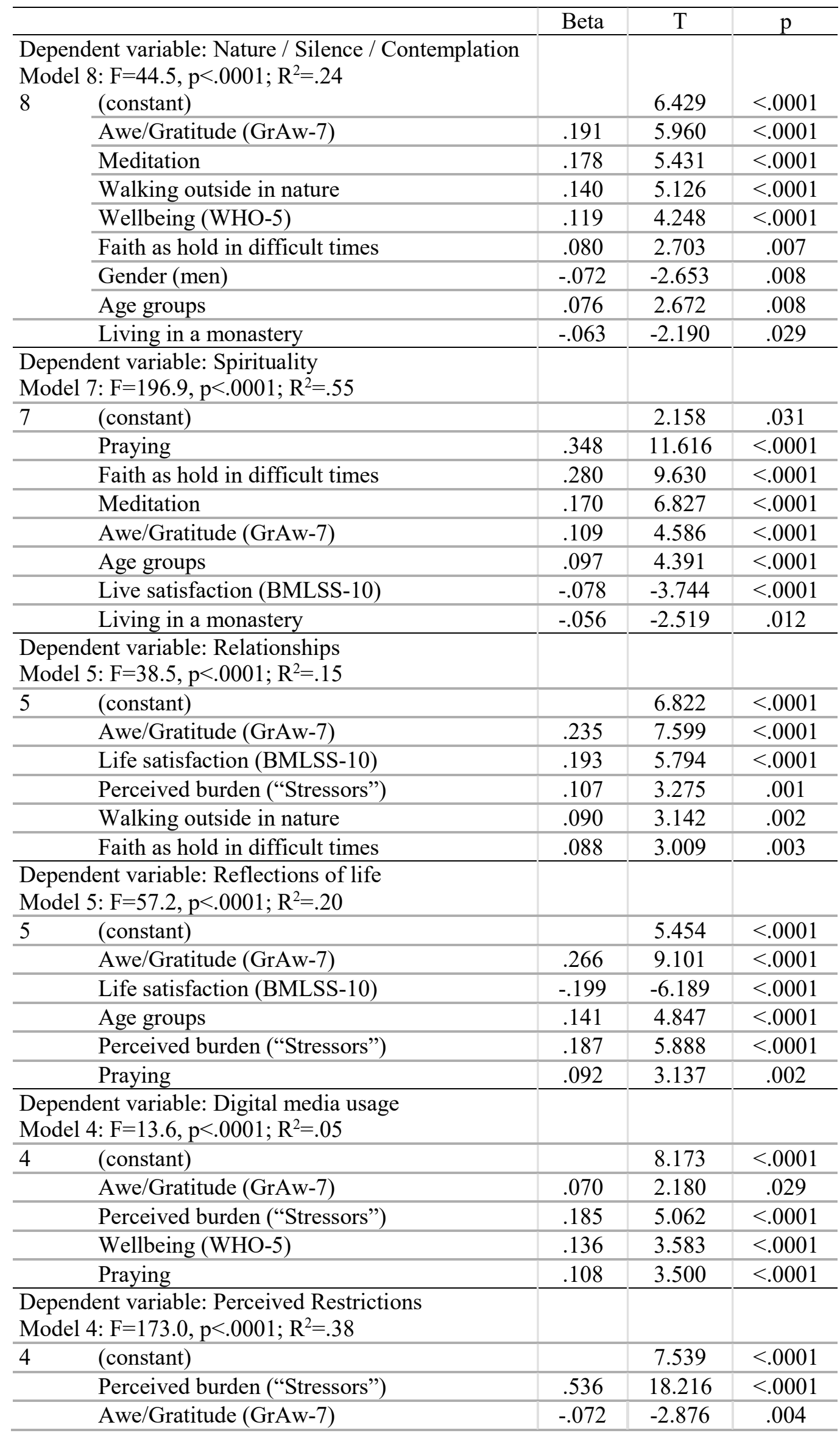




\begin{tabular}{l|c|c|c}
\hline Wellbeing (WHO-5) & -.103 & -3.359 & .001 \\
\hline Gender (men) & .057 & 2.371 & .018 \\
\hline
\end{tabular}

Table 6: General predictors of wellbeing (stepwise regression analyses)

\begin{tabular}{|c|c|c|c|c|}
\hline \multicolumn{2}{|c|}{$\begin{array}{l}\text { Dependent variable: Wellbeing (WHO-5) } \\
\text { Model 9: } \mathrm{F}=135.7, \mathrm{p}<.0001 ; \mathrm{R}^{2}=.51\end{array}$} & \multirow[t]{2}{*}{ Beta } & \multirow{2}{*}{$\frac{\mathrm{T}}{4.359}$} & \multirow{2}{*}{$\frac{\mathrm{p}}{<.0001}$} \\
\hline$\overline{9}$ & (constant) & & & \\
\hline & Perceived burden (“Stressors") & -.355 & -13.971 & $<.0001$ \\
\hline & Life satisfaction (BMLSS-10) & .329 & 12.596 & $<.0001$ \\
\hline & Awe/Gratitude (GrAw-7) & .145 & 6.069 & $<.0001$ \\
\hline & Age groups & .086 & 3.910 & $<.0001$ \\
\hline & Changes: Nature / Silence / Contemplation & .143 & 4.927 & $<.0001$ \\
\hline & Changes: Reflections of life & -.102 & -3.770 & $<.0001$ \\
\hline & Gender (women) & .062 & 2.908 & .004 \\
\hline & Changes: Digital media usage & .063 & 2.876 & .004 \\
\hline & Changes: Relations & -.065 & -2.456 & .014 \\
\hline
\end{tabular}

Variables without a significant relevance in this model: Living in a monastery, Changes: Spirituality, and Changes: Restrictions 
Figures

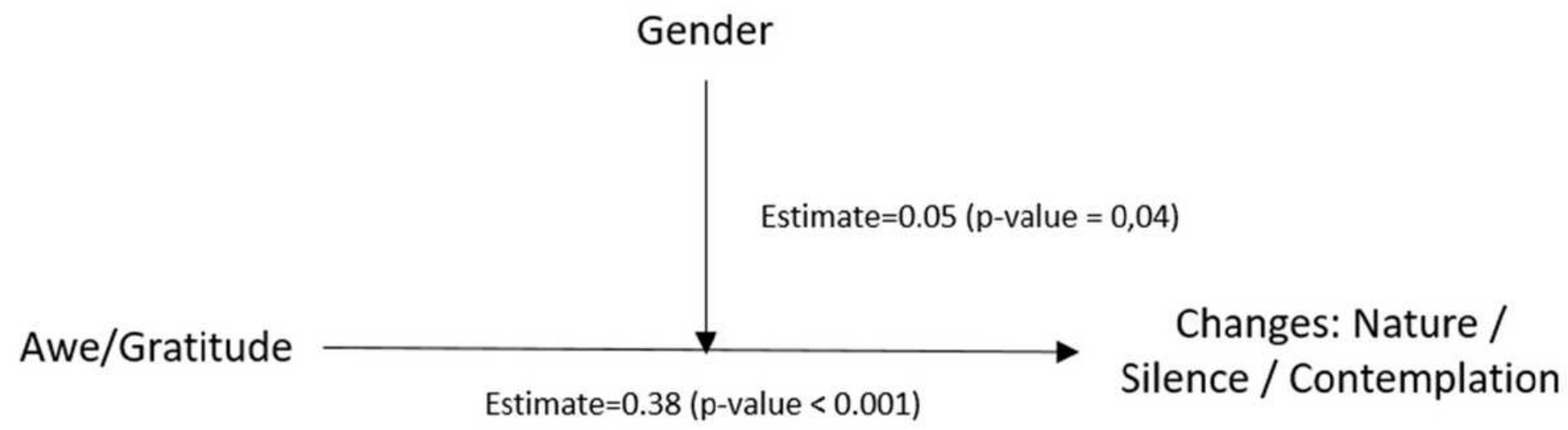

Figure 1

Moderation model for gender 